\title{
DIRECTIVAS COMUNITARIAS Y COMUNIDADES AUTÓNOMAS: EL DERECHO PATRIMONIAL
}

\author{
LUIS MARÍA DÍEZ-PICAZO \\ Catedrático de Derecho Constitucional
}

Universidad de Málaga 


\section{SUMARIO}

I. INTROdUCCIÓN. II. RefERENCIA A LA DIRECTIVA COMO TIPO NORMATIVO DEL DERECHO comunitario. III. Estado y Comunidades Autónomas en la tRansposición de diRECTIVAS: LA JURISPRUDENCIA CONSTITUCIONAL ESPAÑOLA. IV. EL PRINCIPIO DE AUTONOMÍA INSTITUCIONAL EN LA JURISPRUDENCIA COMUNITARIA. V. CONCLUSIÓN. VI. Nota BIBLIOGRÁFICA. 


\title{
DIRECTIVAS COMUNITARIAS Y COMUNIDADES AUTÓNOMAS: EL DERECHO PATRIMONIAL (*)
}

POR

\author{
LUIS MARÍA DÍEZ-PICAZO \\ Catedrático de Derecho Constitucional \\ Universidad de Málaga
}

\section{INTRODUCCIÓN}

La transposición de directivas en materia de derecho patrimonial por parte de las Comunidades Autónomas no plantea, en principio, problemas especificos; es decir, salvo alguna peculiaridad a que se hará mención más adelante, los interrogantes suscitados por la transposición de directivas por parte de las Comunidades Autónomas son siempre los mismos, independientemente de la materia sobre la que versen aquéllas. Ello se debe a que, para decidir cuándo, cómo y dentro de qué límites pueden las Comunidades Autónomas transponer directivas, el criterio decisivo viene dado por el orden constitucional y estatutario de distribución de competencias; y, por ello, tratándose de directivas que afectan al derecho patrimonial, habrá que estar a los diferentes títulos competenciales que cada Comunidad Autónoma pueda invocar en dicha esfera. Dado que las dos ponencias anteriores, ade-

(*) Este texto se corresponde con una conferencia pronunciada en las $X$ Jornadas de Derecho Catalán, el día 17-IX-1998. 
más, han analizado las competencias de Cataluña que afectan al derecho patrimonial, sería ocioso abundar sobre el tema: parece preferible concentrarse sobre la transposición de directivas por parte de las Comunidades Autónomas en general, en la plena consciencia de que su régimen jurídico es aplicable cuando de derecho patrimonial se trata.

A la hora de establecer cuál es ese régimen juridico de la transposición de directivas por parte de las Comunidades Autónomas, es preciso tener en cuenta que esta materia presenta una doble dimensión: de derecho nacional y de derecho comunitario. De aquí que una visión completa exija examinar tanto las normas nacionales como las normas comunitarias relevantes en esta materia, pues sólo así será posible comprobar hasta qué punto las respuestas de ambos ordenamientos resultan coherentes entre sí. Puede ser útil, sin embargo, comenzar por hacer alguna referencia a las principales características de la directiva como tipo normativo, incluidas las exigencias inherentes al deber de transposición que pesa sobre los Estados miembros.

\section{REFERENCIA A LA DIRECTIVA COMO TIPO NORMATIVO DEL DERECHO COMUNITARIO}

La idea de directiva se halla definida, como es notorio, en el art. 189 del Tratado de la Comunidad Europea en los siguientes términos:

"La directiva obligará al Estado miembro en cuanto al resultado que deba conseguirse, dejando, sin embargo, a las autoridades nacionales la elección de la forma y de los medios."

Cabe afirmar, por tanto, que la directiva se limita a fijar determinados objetivos cuya consecución queda encomendada a normas nacionales, de manera que son éstas últimas, no la directiva misma, las que regulan la materia de que se trate. La operación consistente en elaborar y aprobar dichas normas nacionales tendentes a realizar los objetivos fijados por la directiva es, precisamente, lo que se suele designar con el término "transposición". Así, en cuanto tipo normativo, la directiva comporta un menor grado de intrusión en los ordenamientos de los Estados miembros que el reglamento: mientras éste contiene una regulación completa e inmediatamente vinculante tanto para las autoridades como para los particulares, aquélla deja cierto margen 
de apreciación sobre los medios más idóneos habida cuenta de las concretas características nacionales.

Aún así, la puntual y correcta transposición de las directivas resulta de crucial importancia, pues de ella depende el llamado «efecto útil» - esto es, el cumplimiento de la finalidad que, dentro del marco de los Tratados constitutivos, persiguen las instituciones comunitarias al adoptar una norma - $y$, en definitiva, la uniforme aplicación del derecho comunitario en todo el territorio de la Unión Europea. De aquí que todo Estado miembro esté siempre obligado a la transposición de cada directiva, sin que pueda argüir que su ordenamiento interno satisfacía ya las exigencias de aquélla: según el Tribunal de Justicia de las Comunidades Europeas, sólo en aquellos casos excepcionales en que el derecho nacional anterior, además de adecuarse a lo impuesto por la directiva, sea absolutamente claro y preciso cabría una dispensa del deber de transposición. Asi, por ejemplo, la sentencia Comisión c. Alemania (1985).

A la vista de todo lo anterior, no es de extrañar la atención que el Tribunal ha prestado a la no infrecuente reticencia de los Estados miembros a una transposición puntual y correcta de las directivas. En este orden de ideas, a fin de minimizar las consecuencias negativas de una transposición omitida o defectuosa, la jurisprudencia comunitaria ha diseñado tres mecanismos:

1. Ante todo, se halla la doctrina de la eficacia directa de las directivas, inaugurada por la sentencia Van Duyn c. Home Office (1974): se trata de neutralizar las consecuencias de la falta de transposición de una directiva simplemente mediante la atribución a la misma de fuerza vinculante inmediata. Aparte de no estar expresamente excluida por el art. 189 del Tratado de la Comunidad Europea, la eficacia directa de las directivas puede hallar cierto apoyo textual en el hecho de que el art. 177 del propio Tratado permite que las directivas sean objeto de cuestión prejudicial ante el Tribunal de Justicia de las Comunidades Europeas, de donde se infiere su aplicabilidad por el juez nacional. Para poseer eficacia directa, no obstante, una directiva debe reunir tres requisitos: a) que no haya sido transpuesta en el plazo establecido al efecto o, en su caso, que la transposición sea defectuosa; $b$ ) que reconozca derechos a particulares; c) que tenga un contenido normativo claro, preciso e incondicionado. Una directiva con eficacia directa es oponible tanto frente al Estado como frente a cualesquiera otras autoridades públicas que operen en su interior (Fratelli Costanzo c. Comune di Milano, 1986) y, además, independientemente de la condición, de 
derecho público o de derecho privado, en que actúen (Marshall $c$. Southampton and Southwest Area Health Authority, 1986). Además, tratándose de una directiva con finalidad liberalizadora, su eficacia directa supone la licitud de la conducta que el derecho nacional tipifica, en vía penal o administrativa, como antijurídica (Pubblico Ministero $c$. Ratti, 1979). Debe tenerse en cuenta que el enorme potencial de esta doctrina para combatir la reticencia de los Estados miembros ha provocado una mutación gradual de la técnica legislativa en las instituciones políticas comunitarias, de manera que las directivas tienden a ser redactadas con un grado de precisión tal que a menudo resultan difícilmente diferenciables de los reglamentos.

2. La eficacia directa, sin embargo, no proporciona remedio alguno para la no transposición de aquellas directivas cuya finalidad es regular relaciones entre particulares; y ello porque, a pesar de la insistencia de algunos Abogados Generales, el Tribunal se ha negado hasta ahora a afirmar la posibilidad de que las directivas tengan eficacia directa "horizontal». Tras esta negativa, aparte de consideraciones relativas a la seguridad jurídica, late la consciencia de que a ninguna de las partes de la relación jurídica contemplada por la directiva puede serle imputada la falta de transposición $y$, por consiguiente, que su eventual eficacia directa carecería de efectos disuasorios para el Estado incumplidor. Ello no ha impedido que, tratándose de relaciones entre particulares, el Tribunal haya intentado buscar un equivalente funcional de la doctrina de la eficacia directa por otra vía: a partir de la sentencia Marleasing S.A. c. Sociedad Internacional de Alimentación $S . A$. (1990), la jurisprudencia comunitaria exige que el juez nacional haga el máximo esfuerzo posible para interpretar el derecho nacional, anterior o posterior a la directiva no transpuesta, de manera tal que pueda alcanzarse el objetivo de la misma.

3. La eficacia directa tampoco da solución satisfactoria a la no transposición de aquellas directivas que, aun reconociendo derechos a los particulares frente al Estado, no pueden prescindir de la colaboración activa de éste último. Este es, señaladamente, el caso de las directivas que prevén prestaciones y servicios públicos. La respuesta del Tribunal a este tipo de situaciones ha sido la afirmación puramente jurisprudencial, sin base textual alguna en los Tratados constitutivos, de la responsabilidad extracontractual de los Estados miembros. En efecto, desde la sentencia Francovich y Bonifaci c. Italia (1991), el Estado está obligado a indemnizar a los particulares por los daños que les haya 
irrogado la no transposición siempre que se cumplan las siguientes condiciones: a) que la directiva otorgue derechos a los particulares; $b$ ) que el contenido de esos derechos sea identificable a partir de la directiva misma; c) que exista un nexo causal entre la transposición omitida o defectuosa y el daño sufrido. La acción de responsabilidad habrá de ejercerse por los cauces previstos en el correspondiente derecho nacional, si bien éstos no podrán ser excesivamente complejos ni más gravosos que los aplicables a situaciones puramente internas de naturaleza análoga. Téngase en cuenta que, más allá de los supuestos de no transposición de directivas, la sentencia Brasserie du Pêcheur S.A. c. Alemania (1996) ha ampliado la responsabilidad extracontractual de los Estados miembros hasta cubrir los daños ocasionados a particulares por cualquier "violación suficientemente caracterizada" del derecho comunitario. No es ocioso recordar, por lo demás, que el incumplimiento de deberes comunitarios por los Estados miembros puede dar lugar, a partir de la reforma introducida por el Tratado de Maastricht en el art. 171 del Tratado de la Comunidad Europe, a responsabilidad pecuniaria exigible por la Comisión ante el Tribunal de Justicia de las Comunidades Europeas.

\section{ESTADO Y COMUNIDADES AUTONÓMAS}

EN LA TRANSPOSICIÓN DE DIRECTIVAS: LA JURISPRUDENCIA CONSTITUCIONAL ESPAÑOLA

Dentro de la jurisprudencia constitucional española que hace referencia al derecho comunitario, el problema de delimitación competencial entre el Estado y las Comunidades Autónomas a la hora de transponer directivas ha sido indudablemente el que, en términos cuantitativos, más ha ocupado la atención del Tribunal Constitucional. En la terminología comunitaria, este problema, que se plantea también en otros Estados miembros dotados de una estructura territorial compuesta, suele denominarse "proceso decisional descendente"; es decir, a qué nivel de gobierno corresponde actuar por vía normativa o administrativa las normas comunitarias.

Pues bien, el principio general establecido por la jurisprudencia constitucional es que la pertenencia de España a la Unión Europea no altera el orden interno de distribución de competencias entre el Estado y las Comunidades Autónomas; y ello, sencillamente, a causa de la inidoneidad de cualesquiera normas comunitarias para modificar normas 
internas de rango constitucional (art. 95 de la Constitución). Es interesante observar cómo el mencionado principio general fue introducido por la primera resolución del Tribunal Constitucional relativa al derecho comunitario: la STC 258/1988. Se trataba de una directiva comunitaria en materia de sanidad animal que disponía expresamente que su transposición habia de efectuarse por la "autoridad central» competente de cada Estado miembro; y, suscitado conflicto de competencia entre Cataluña y el Estado, el Tribunal, habida cuenta de que la materia corresponde a aquélla, estimó que en el territorio catalán autoridad central sólo podía ser la autónomica.

El principio general de la no alteración del orden interno de distribución de competencias ha sido confirmado por una jurisprudencia constitucional constante y prácticamente uniforme. Así, en materia de agricultura (STC 76/1991, 115/1991, 29/1994, 265/1994, 112/1995 y 67/1996), de pesos y medidas (STC 236/1991), de radiodifusión (STC 244/1993), de comercio (STC 80/1993), de sanidad (147/1996) y de gestión de ayudas comunitarias (STC 117/1992). Es más: el Tribunal Constitucional tiende a aplicar idéntico criterio cuando el problema competencial consiste en la mayor o menor extensión que resulta constitucionalmente permisible a la legislación básica; esto es, en aquellas materias de competencia compartida en que al.Estado corresponde sólo dictar un mínimo normativo común a respetar por las distintas legislaciones autonómicas, la pertenencia de España a la Unión Europea y las obligaciones que de ella se derivan no son, por sí solas, argumento suficiente para restringir la potestad legislativa de las Comunidades Autónomas. Así, en materia de contratación pública (STC 141/1993), de ayudas comunitarias (STC 213/1994) y de seguros (STC 330/1997). Es cierto, sin embargo, que en alguna ocasión el Tribunal ha recurrido a la necesidad de salvaguardar la responsabilidad del Estado por el cumplimiento del derecho comunitario como argumento adicional a la hora de determinar el título competencial relevante y, por consiguiente, el margen permisible de legislación básica; pero no sólo es dudoso que se tratara de la genuina ratio decidendi sino que, además, no deja de ser significativo que ello se haya producido en dos casos relativos, respectivamente, a instituciones de crédito (STC 37/1997) v mercado de valores (STC 133/1997), es decir, en dos sectores en que existe una acentuada política comunitaria de unificación normativa entre los Estados miembros.

Esta linea jurisprudencial no ha estado exenta de crítica dentro del propio Tribunal Constitucional: el Magistrado J. González Campos ha puesto repetidamente de manifiesto las incongruencias a que pue- 
de conducir interpretar las normas constitucionales españolas sin tomar en consideración las exigencias comunitarias. Así, por ejemplo, en su voto particular a la mencionada STC 147/1996 discrepó de que se atribuyera al Estado la competencia para transponer una directiva sobre etiquetado de productos alimenticios que permitía el uso de cualquier lengua fácilmente comprensible para los consumidores; y ello porque dicha solución conducía a forzar tanto la norma comunitaria, como las normas nacionales en materia de cooficialidad de las lenguas autonómicas propias.

Mención aparte merece otro aspecto de la jurisprudencia constitucional, que podría resumirse con la siguiente fórmula: el mero hecho de que el derecho comunitario deje libertad de opción a los Estados miembros no implica que las Comunidades Autónomas estén constitucionalmente facultadas para exigir la solución que estimen más favorable a sus intereses. Esta corriente jurisprudencial, que fue inaugurada por la STC 28/1991 - relativa a la Ley 1/1987, de Elecciones al Parlamento Europeo y, por tanto, a la introducción de una circunscripción electoral única para todo el pais-, ha sido aplicada a la transposición de directivas por la STC 146/1996. Se trataba de una directiva sobre formas prohibidas de publicidad comercial que preveía la opción entre mecanismos administrativos o judiciales de control: la preferencia del Estado por un mecanismo judicial de control, que comporta la automática exclusión de las Comunidades Autónomas en la medida en que carecen de una propia administración de justicia, fue considerada una opción constitucionalmente tan lícita como la contraria.

En una perspectiva más general, conviene señalar que las respuestas que el Tribunal Constitucional ha dado a los litigios competenciales entre el Estado y las Comunidades Autónomas sobre la transposición de directivas no pueden ser desvinculadas de la visión global, marcadamente nacionalista, que aquél tiene de las relaciones entre el derecho comunitario y la Constitución española. Esta visión queda patente en resoluciones tales como la STC 64/1991 o la Declaración de 1 de julio de 1992, relativa a la ratificación por España del Tratado de Maastricht: los Tratados constitutivos de la Unión Europea y, con más razón, el derecho comunitario derivado carecen de valor constitucional en el ordenamiento español. Esta afirmación, que en sí misma es correcta, produce, sin embargo, algunas consecuencias perversas; y ello no sólo porque conduce a sostener la absoluta e indiscriminada supremacía de la Constitución a la hora de aplicar el derecho comunitario sino, sobre todo, porque lleva al Tribunal Constitucional a estimar que los problemas jurídicos comunitarios son siempre de legalidad ordina- 
ria $y$, por tanto, ajenos a su jurisdicción. De aquí que, cualquiera que sea la vulneración del derecho comunitario, no quepa impetrar la protección del Tribunal Constitucional; $y$, si bien ello no es particularmente grave por lo que se refiere a las relaciones entre el Estado y las Comunidades Autónomas, no deja de ser preocupante en otros ámbitos, tales como la admisibilidad del recurso de amparo o la negativa injustificada del juez ordinario a plantear la cuestión prejudicial.

Probablemente, las dificultades que se acaban de mencionar podrían superarse si se hiciera una distinción más cuidadosa entre "valor constitucional" y "relevancia constitucional», tal como parece apuntar esporádicamente la propia jurisprudencia constitucional. Así, el ATC 265/1991 o la STC 182/1997. Esta última resolución es interesante, pues estimó que la consecución de la convergencia económica requerida por la unión monetaria constituía un supuesto de "extraordinaria y urgente necesidad" (art. 86 de la Constitución), libremente apreciable por los órganos políticos del Estado a efectos de la utilización del decretoley; y ello significa que, al menos por lo que respecta a los márgenes constitucionalmente admisibles de libertad de apreciación política, las exigencias comunitarias no son del todo irrelevantes. Téngase en cuenta, sin embargo, que esta posibilidad de recurrir al decreto-ley para alcanzar objetivos de índole comunitaria nunca podría alterar el orden constitucional y estatutario de distribución de competencias (STC 29/1986) y, por consiguiente, no podría privar a las Comunidades Autónomas de la facultad de transponer directivas dentro de su esfera competencial.

Dos observaciones adicionales: primera, es sabido que los arts. 148 y 149 de la Constitución no contienen reservas de ley en sentido propio, de donde se sigue que la selección del tipo normativo idóneo para la transposición de directivas, por parte del Estado o de las Comunidades Autónomas, se regirá por los criterios generales del sistema de fuentes; segunda, es lícito afirmar que la jurisprudencia constitucional sobre transposición de directivas es neutral en cuanto a sus resultados prácticos. En efecto, más de la mitad de las sentencias arriba mencionadas resultaron favorables a las Comunidades Autónomas; es decir, no parece que la pertenencia a la Unión Europea haya comportado, en este punto, una pérdida de autogobierno efectivo por parte de las Comunidades Autónomas. 


\section{EL PRINCIPIO DE AUTONOMÍA INSTITUCIONAL EN LA JURISPRUDENCIA COMUNITARIA}

Desde el punto de vista del derecho comunitario, el llamado "proceso decisional descendente" es, en principio, una cuestión interna de los Estados miembros: el art. F del Tratado de Maastricht sólo exige que éstos tengan un régimen democrático y respetuoso hacia los derechos humanos; lo que, como es obvio, les deja un amplísimo margen de libertad para dotarse de la organización constitucional que estimen más conveniente. La pertenencia a la Unión Europea, en otras palabras, no prejuzga la estructura y el funcionamiento internos de los Estados miembros.

A partir de estas premisas, el Tribunal de Justicia de las Comunidades Europeas ha afirmado la existencia del principio de autonomía institucional de los Estados miembros. Conviene subrayar que se trata de un principio general del derecho comunitario, en virtud del cual cabe sostener que el cumplimiento de los deberes que emanan de la pertenencia a la Unión Europea no exige normalmente a los Estados miembros específicas formas organizativas o procedimentales. Su formulación clásica se remonta a la sentencia International Fruit Company c. Produktschap voor Groenten en Fruit (1971):

"Cuando las disposiciones del Tratado o de reglamentos reconocen poderes o imponen obligaciones a los Estados miembros a efectos de la aplicación del derecho comunitario, la cuestión de saber de qué manera el ejercicio de esos poderes y la ejecución de esas obligaciones pueden ser encomendados por los Estados a determinados órganos depende únicamente del sistema constitucional de cada Estado.»

La afirmación del principio de autonomía institucional trae consigo, al menos, dos consecuencias: por un lado, el Tribunal de Justicia de las Comunidades Europeas no es jamás competente para resolver los litigios competenciales que, aún versando sobre la aplicación del derecho comunitario, puedan surgir entre distintas autoridades de un mismo Estado miembro (Rewe Zentralfinanz c. Landwirtschaftkamer für das Saarland, 1976); por otro lado, el reparto territorial del poder político dentro de cada Estado miembro resulta intangible para las instituciones comunitarias (Alemania c. Comisión, 1990). En palabras de esta última sentencia: 
"Corresponde a todas las autoridades de los Estados miembros, se trate de autoridades del poder central del Estado, de autoridades de un Estado federado o de otras autoridades territoriales, asegurar el respeto de las normas del derecho comunitario en el marco de sus competencias. Por el contrario, no corresponde a la Comisión pronunciarse sobre el reparto de competencias operado por las reglas institucionales de cada Estado miembro ni sobre las obligaciones que, en un Estado dotado de una estructura federal, puedan corresponder respectivamente a las autoridades federales $y$ a las autoridades de los Estados federados. Aquélla no puede sino controlar si el conjunto de medidas de vigilancia y control establecido según las modalidades del orden jurídico nacional es suficientemente eficaz para permitir una aplicación correcta de los principios comunitarios."

A fin de comprender el exacto alcance del principio de autonomía institucional, es inexcusable tener presente, además, la distinción operada por la sentencia Rewe Handelgesellschaft Nord MBH c. Hauptzollamt Kiel (1981) entre "vías de derecho" y "acciones directas": la primera expresión designa los procedimientos (normativos, administrativos, jurisdiccionales) a través de los cuales se da aplicación al derecho comunitario en el interior de los Estados miembros, mientras la segunda hace referencia a los derechos y deberes creados por normas comunitarias, que incluyen eventualmente remedios frente a su inobservancia (aplicación directa, responsabilidad extracontractual, etc.). Pues bien, a diferencia de las "vías de derecho", las "acciones directas" no están cubiertas por el principio de autonomía institucional; y ello, sencillamente, porque no pertenecen al ámbito de lo organizativo y procedimental, sino al de lo estrictamente sustantivo.

Es cierto que la jurisprudencia comunitaria ha ido introduciendo, especialmente en los últimos años, algunas restricciones al principio de autonomia institucional; pero no deja de ser significativo que hayan afectado, sobre todo, a las facultades de los jueces nacionales a la hora de dar aplicación al derecho comunitario: véanse la celebérrima sentencia The Queen c. Secretary of State for Transport, ex parte Factortame (1990) y su progenie. Desde el punto de vista de la estructura territorial de los Estados miembros, en cambio, el principio de autonomía institucional se halla sustancialmente intacto. Sólo tiene dos límites, que se desprenden de su propia naturaleza: primero, sobre los Estados miembros pesa el deber de coordinar a todas sus autoridades (centrales y territoriales) a fin de asegurar la efectiva y correcta aplicación del derecho comunitario, tal como se desprende de la sentencia Atlanta Amsterdam c. Produktschap voor Vee en Vlees (1979) y de la ya 
citada Alemania c. Comisión (1990); segundo, el carácter constitucionalmente independiente de determinadas autoridades, incluidas las de carácter judicial, no exime de responsabilidad a los Estados miembros por el incumplimiento del derecho comunitario, tal como se afirma en la sentencia Comisión c. Italia (1991). Así, la responsabilidad directa del Estado miembro, frente a la Unión Europea o frente a los particulares, es el contrapeso a la no interferencia de las instituciones comunitarias en su organización constitucional.

Es preciso, por lo demás, deshacer un posible equívoco: el principio de subsidiariedad, proclamado por el Tratado de Maastricht, en nada afecta al principio de autonomía institucional. Así se infiere del propio tenor literal del apartado segundo art. 3 B del Tratado de la Comunidad Europea, donde encuentra expresión normativa:

«En los ámbitos que no sean de su competencia exclusiva, la Comunidad intervendrá, conforme al principio de subsidiariedad, sólo en la medida en que los objetivos de la acción pretendida no puedan ser alcanzados de manera suficiente por los Estados miembros $y$, por consiguiente, puedan lograrse mejor, debido a la dimensión o a los efectos de la acción contemplada, a nivel comunitario.»

Es claro, pues, que el principio de subsidiariedad sólo regula la delimitación de ámbitos de actuación comunitarios y estatales. Dicho de otro modo, en cuanto parte integrante del derecho comunitario, el principio de subsidiariedad no tiene voz en capítulo acerca de cuál sea el nivel de gobierno más idóneo dentro de cada Estado miembro para adoptar cualesquiera decisiones. Ciertamente, el significado jurídico del principio de subsidiariedad dista de ser claro; pero, en todo caso, el debate nunca ha girado en torno a su posible aplicación en el interior de los Estados miembros. Antes al contrario, en el apartado 5 de su Declaración de Birmingham de 16 de octubre de 1992 sobre el principio de subsidiariedad, el Consejo Europeo cierra expresamente el paso a cualquier tentación de esa índole al afirmar:

"Corresponde a cada Estado miembro decidir cómo deben ejercerse nacionalmente sus poderes.» 


\section{CONCLUSIÓN}

A la vista de todo cuanto precede, cabe afirmar que, en cuanto a la transposición de directivas por parte de las Comunidades Autónomas, existe una coincidencia de la "lógica constitucional» y la "lógica comunitarian: el principio constitucional de no alteración del orden interno de distribución de competencias y el principio comunitario de autonomía institucional conducen, en este punto, a resultados sustancialmente idénticos. De aquí que, en general, las Comunidades Autónomas puedan y deban transponer las directivas siempre que, por razón de la materia, ostenten constitucional y estatutariamente la correspondiente competencia legislativa. Ni que decir tiene que ello es predicable, en particular, de aquellas directivas que incidan sobre el derecho patrimonial.

Que las Comunidades Autónomas puedan y deban transponer las directivas en materias de su competencia comporta, a su vez, una serie de consecuencias:

1. Las Comunidades Autónomas están plenamente sujetas a los remedios frente a la falta de transposición de las directivas. Ello significa que, si se reúnen las condiciones exigidas, les será oponible la eficacia directa, incluso cuando actúen, directamente o a través de entidades instrumentales, con sometimiento al derecho privado. Ciertamente, al incidir sobre relaciones entre particulares, las directivas en materia de derecho patrimonial no admitirán a menudo eficacia directa; pero su falta de transposición habrá de ser remediada mediante una interpretación del derecho nacional (estatal y autonómico) en vigor compatible con el objetivo de aquéllas.

2. Las disposiciones, legales o reglamentarias según los casos, adoptadas por las Comunidades Autónomas para la transposición de directivas son, a todos los efectos, derecho autonómico. Esta afirmación, como es obvio, es relevante a la hora de determinar su esfera personal y territorial de aplicabilidad; pero tiene una especial importancia práctica, además, cuando de derecho patrimonial se trata: usualmente serán normas de derecho privado y, en aquellas Comunidades Autónomas con competencias de conservación y desarrollo de su derecho foral o especial, tenderán a quedar integradas en éste último. En este supuesto, es claro que de las disposiciones autonómicas de transposición de directivas es predicable la competencia de la Sala de lo Civil y Penal del correspondiente Tribunal Superior de Justicia para conocer 
de de los recursos de casación y de revisión (art. 73 de la Ley Orgánica del Poder Judicial).

3. La transposición de directivas por las Comunidades Autónomas está sometida a las facultades estatales de vigilancia y coordinación. Ahora bien, si la competencia legislativa necesaria para la transposición corresponde a las Comunidades Autónomas, el Estado no podrá sustituirse a aquéllas, ni siquiera invocando la "extraordinaria y urgente necesidad" que constituye el presupuesto habilitante para la utilización del decreto-ley. La única posibilidad de sustitución estatal parece ser la contemplada, ciertamente para supuestos de excepcionales, por el art. 155 de la Constitución; es decir, sería necesario que la falta de transposición de una directiva "atente gravemente contra el interés general de España" y que el Senado autorice por mayoría absoluta al Gobierno a adoptar las medidas oportunas.

4. Toda acción de responsabilidad, ejercida tanto por la Unión Europea como por los particulares, fundada en la falta de transposición de las directivas puede recaer directamente sobre el Estado, sin que éste pueda escudarse en que la omisión es imputable a las Comunidades Autónomas. Ahora bien, esta responsabilidad directa del Estado prevista por el derecho comunitario no parece ser incompatible con otras dos posibilidades: primera, que el particular lesionado se dirija contra la Comunidad Autónoma que dejó de transponer la directiva, pues ello es ajustado a las normas españolas sobre responsabilidad administrativa (art. 139 y siguientes de la Ley de Régimen Jurídico de las Administraciones Públicas) y, además, no es incompatible con las exigencias comunitarias; segunda, que el Estado pueda ejercer, de acuerdo con los principios generales del derecho de daños, una acción de regreso frente a aquella Comunidad Autónoma por cuya omisión fue condenado al resarcimiento.

\section{NOTA BIBLIOGRÁFICA}

Sobre la relación entre integración europea y estructura territorial del Estado, en la bibliografía relativamente reciente, hay que mencionar los volúmenes de P. Pérez Tremps, Constitución española $y$ Comunidad Europea, Civitas, Madrid, 1994 y de E. Albertí Rovira, Autonomía política y unidad económica, Civitas, Madrid, 1995. Para un 
análisis de conjunto de la jurisprudencia del Tribunal Constitucional sobre la pertenencia de España a la Unión Europea, permítase la remisión a mi trabajo "El derecho comunitario en la jurisprudencia constitucional españolan, en curso de publicación en la Revista Española de Derecho Constitucional.

El régimen jurídico de las directivas es analizado en cualquier obra de referencia de derecho comunitario. No ocurre lo propio, sin embargo, con el principio de autonomía institucional. Un examen exhaustivo del mismo puede encontrarse en el libro de J. Rideau, Droit institutionnel de l'Union et des Communautés européennes, 2. ${ }^{\text {a }}$ ed., L.G.D.J., Paris, 1996, p. 727 ss. Véase, asimismo, G. Gaja, Introduzione al diritto comunitario, Laterza, Roma/Bari, 1996, p. 5 ss. y 81 ss., así como Centre for Economic Policy Research, La distribuzione dei poteri nell'Unione Europea (trad. it.), II Mulino, Bologna, 1995, en especial p. 23 ss. Por lo demás, la Declaración de Birmingham de 16 de octubre de 1992 puede ser consultada en E. García de Enterría, A. Tizzano y R. Alonso García, Código de la Unión Europea, Civitas, Madrid, 1996, p. 795-796.

En fin, sobre la responsabilidad por incumplimiento del derecho comunitario, cabe remitirse al estudio de S. Muñoz Machado, «La creación de un sistema único de responsabilidad civil en el espacio europeo", recogido en su libro La Unión Europea y las mutaciones del Estado, Alianza Editorial, Madrid, 1993, p. 101 ss. 